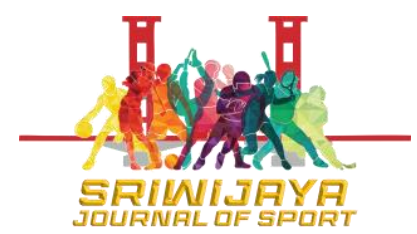

Sriwijaya Journal of Sport

Volume 1, Nomor 1, Oktober 2021: 38-46

http://ejournal.fkip.unsri.ac.id/index.php/sjs e-ISSN 2808-5299

p-ISSN 2808-5701

\title{
Peningkatan hasil belajar menggiring sepak bola melalui pendekatan permainan
}

\section{Improved learning outcomes of dribbling football through a game approach}

\section{Hengki Kumbara ${ }^{*}, 1$, Muhammad Tri Bintang Muharom ${ }^{1}$, Dian Nuzulia ${ }^{1}$}

${ }^{1}$ Pendidikan Jasmani, Universitas PGRI Palembang, Palembang, Indonesia

${ }^{*}$ Corresponding Author

\begin{abstract}
Abstrak
Tujuan penelitian ini adalah untuk meningkatkan hasil belajar dribbling pada materi sepak bola. Metode penelitian yang akan digunakan dalam penelitian ini adalah pre-experiment design dengan rancangan perlakuan pada penelitian ini menggunakan one-group pretest-posttest. Sampel penelitian ini adalah kelas XI IPS 1 yang berjumlah 32 peserta didik. Penentuan sampel menggunakan teknik sampling cluster random sampling. Untuk menilai kemampuan dribbling adalah Soccer Battery. Hasil penelitian menunjukkan bahwa ada perbedaan kemampuan dribbling peserta didik sebelum dan sesudah pemberian perlakuan, yaitu pembelajaran dengan pendekatan permainan. Maka kesimpulan dari penelitian ini adalah pembelajaran dengan pendekatan bermain dapat meningkatkan hasil belajar dribbling peserta didik pada satuan pendidikan Sekolah Menengah Atas.
\end{abstract}

Kata Kunci: Menggiring; Permainan; Pendekatan; Sepak Bola.

\begin{abstract}
The purpose of this study was to improve dribbling learning outcomes in soccer material. The research method that will be used in this study is a pre-experimental design with the treatment design in this study using a one-group pretest-posttest. The sample of this research is class XI IPS 1 which consists of 32 students. Determination of the sample using cluster random sampling technique. To assess dribbling ability is Soccer Battery. The results showed that there were differences in the dribbling abilities of students before and after giving treatment, namely learning with a game approach. Conclusion of this study is that learning with a play approach can improve students' dribbling learning outcomes in high school education units.
\end{abstract}

Keywords: Dribbling; Game; Approach; Football.

Received: 1 October 2021; Revised: 18 October 2021; Accepted: 26 October 2021

Corresponding author: Hengki Kumbara, JL. Jend. A. Yani Lrg. Gotong Royong Palembang

Email: hengkikumbara88@gmail.com

\section{PENDAHULUAN}

Pendidikan adalah segala pengalaman belajar yang berlangsung dalam segala lingkungan dan sepanjang hidup. Pendidikan adalah segala situasi hidup yang mempengaruhi pertumbuhan individu (Susanto, 2016). Secara umum, fungsi pendidikan adalah untuk menggembangkan kemampuan, 
membentuk watak, kepribadian, agar peserta didik menjadi pribadi bermartabat. Pembelajaran merupakan komunikasi dua arah yang dilakukan oleh pihak guru sebagai pendidik, sedangkan belajar dilakukan oleh peserta didik. Pembelajaran adalah segala sesuatu yang dapat membawa informasi dan pengetahuan dalam interaksi yang berlangsung antara pendidik dengan peserta didik (Rusman, 2013). Belajar merupakan suatu proses perubahan tingkah laku sebagai hasil dari interaksi dengan lingkungannya dalam menentukan kebutuhan hidupnya dan belajar juga merupakan pengetahuan melalui alat indra yang disampaikan dalam bentuk perangsang-perangsang dari luar (Abdullah, 2012).

Pendidikan jasmani adalah sebagai tahap proses pendidikan menyeluruh yang berhubungan dengan perkembangan dan pendayagunaan kemampuan yang disengaja dan juga mempunyai tujuan, secara langsung berkaitan dengan respon mental, emosional, dan sosial (Bailey, 2018). Sehingga pendidikan jasmani bukan hanya penilaian hasil pencapaian tugas gerak yang telah dilaksanakan peserta didik. Olahraga dan pendidikan jasmani tidak bisa dipisahkan karena merupakan bagian dan saling mempengaruhi satu sama lainya. Olahraga cukup mendominasi muatan kurikulum pendidikan jasmani pada semua tingkatan satuan pendidikan (Martin \& Morris, 2013). Demikian juga dalam praktik olahraga ini juga sangat digemari, baik oleh guru maupun oleh peserta didik.

Sepak bola merupakan salah satu cabang olahraga yang paling banyak diminati penduduk dunia, tidak terkecuali di indonesia. Olahraga ini memiliki tujuan, yaitu meraih kemenangan dengan mencetak gol sebanyak mungkin ke gawang lawan yang dibangun dari tiang dan berjaring, 11 pemain yang merumput dalam satu tim terdiri atas sepuluh pemain di tengah lapangan dan satu orang penjaga gawang yang bertugas mengamankan gawang dari serangan lawan (Saputra \& Maidarman, 2019). Dalam olahraga sepak bola setiap tim saling bersaing menguasai permainan agar dapat memenangkan pertandingan, pemain juga dibekali dengan teknik permainan yang baik, salah satunya kemampuan dribbling. 
Dribbling merupakan teknik menggiring bola dengan kaki untuk menuju ke titik tertentu atau ke pertahanan lawan atau menendang terputus-putus atau pelan-pelan, oleh karena itu, bagian kaki yang digunakan dalam menggiring bola sama dengan bagian-bagian kaki yang digunakan untuk menendang bola (Irawan \& Hariadi, 2019). Tujuan dari dribbling untuk dapat mendekatkan jarak ke sasaran lawan, melewati lawan, dan juga dapat menghambat serangan lawan. Dribbling merupakan salah satu keterampilan individu yang harus dikuasai oleh setiap pemain sepak bola karena sangat erat hubungannya dengan penguasaan bola di lapangan, karena bola harus selalu berada dalam penguasaan (M. R. E. Saputra \& Yunus, 2019). Menggiring bola harus mampu dilakukan baik tanpa lawan maupun melewati lawan dengan berbagai teknik penguasaan bola.

Berdasarkan pengamatan peneliti rendahnya hasil belajar dribbling menjadi masalah utama terhadap keterbatasan belajar sepak bola peserta didik. Dari 13 rombongan belajar (rombel) kelas XI di SMA Negeri 10 Palembang hanya 5 rombel yang dinyatakan tuntas KKM, sementara 8 kelas belum tuntas. Penyebab permasalahan tersebut adalah: a) guru hanya menggunakan metode ceramah dalam belajar; b) interaksi pembelajaran hanya bersifat satu arah; c) pembelajaran terkesan monoton; dan d) blum pernah diberikan jenis-jenis metode permainan dalam belajar dribbling.

Metode permainan dapat menjadi alternatif bagi guru dalam meningkatkan kemampuan teknik dan hasil belajar peserta didik. Hal tersebut sesuai dengan pernyataan (Amirzan \& Sumarjo, 2021) menyatakan bahwa permainan merupakan cara yang dapat digunakan untuk membantu proses pembelajaran pendidikan jasmani dan menunjang tercapainya tujuan belajar. Manfaat dari permainan akan mengembangkan kecakapan fisik siswa dan membantu mereka tetap sehat dan bugar. Permainan akan membuat siswa menjadi kuat secara emosional, mendorong kreativitas, dan memungkinkan anak untuk berimajinasi. 


\section{METODE}

Metode penelitian yang akan digunakan dalam penelitian ini adalah pre-experiment design dengan rancangan perlakuan pada penelitian ini menggunakan one-group pretest-posttest. Sampel penelitian ini adalah kelas XI IPS 1 yang berjumlah 32 peserta didik. Penentuan sampel menggunakan teknik sampling cluster random sampling. Untuk menilai kemampuan dribbling adalah Soccer Battery dengan nilai validitas 0,78 dan nilai raliabilitasnya adalah 0,64-0,91 (Lacy \& Williams, 2018). Teknik analisis data menggunakan uji beda paired sampel t-test dengan menggunakan aplikasi program SPSS versi 25 dengan tingkat signifikasi $a=0,05$.

\section{HASIL}

Berdasarkan tabel 1dapat dijelaskan bahwa siswa yang meraih nilai hasil belajar kemampuan dribbling sepak bola dengan interval 60-65 sebanyak 7 peserta didik, 66-70 sebanyak 9 peserta didik, tidak ada peserta didik yang mencapai nilai 71-75, sedangkan nilai 76-80 sebanyak 15 peserta didik, tidak ada peserta didik yang mencapai nilai $81-85$, dan 80-90 sebanyak 1 orang peserta didik.

Tabel 1. Data Hasil Pretest

\begin{tabular}{ccc}
\hline Kelas Interval & Frekuensi & Persentase \\
\hline $60-65$ & 7 & $21,9 \%$ \\
$66-71$ & 9 & $28,1 \%$ \\
$72-77$ & 0 & $0 \%$ \\
$78-83$ & 15 & $46,9 \%$ \\
$84-89$ & 0 & $0 \%$ \\
$90-95$ & 1 & $3,13 \%$ \\
\hline Jumlah & $\mathbf{3 2}$ & $\mathbf{1 0 0}$ \\
\hline
\end{tabular}

Berdasarkan tabel 2 dapat dipaparkan bahwa peserta didik mencapai hasil belajar dengan nilai 70-72 sebanyak 2 peserta didik, 73-75 sebanyak 3 peserta didik, tidak ada peserta didik yang mencapai nilai 76-78, 78-81 sebanyak 19 peserta didik, tidak ada siswa yang mencapai nilai 82-84 dan sebanyak 8 orang peserta didik mencapai nilai 85-90.

Tabel 2. Data Hasil Posttest

\section{Kelas Interval Frekuensi Persentase}




\begin{tabular}{ccc}
\hline Kelas Interval & Frekuensi & Persentase \\
\hline $70-73$ & 2 & $6,25 \%$ \\
$74-77$ & 3 & $9 \%$ \\
$78-81$ & 0 & $0 \%$ \\
$82-85$ & 19 & $59 \%$ \\
$86-89$ & 0 & $0 \%$ \\
$90-93$ & 8 & $25 \%$ \\
\hline Jumlah & $\mathbf{3 2}$ & $\mathbf{1 0 0}$ \\
\hline
\end{tabular}

Uji normalitas adalah sebuah pengujian yang dilakukan untuk mengecek apakah data yang sedang diteliti berasal dari populasi yang mempunyai sebaran normal (Sudjana, 2011). Dalam penelitian ini, untuk melakukan uji normalitas adalah menggunakan teknik One Sample Kormogolov-Smirnov Tets. Adapun hasil pengujiannya dapat dilihat pada tabel 3 di bawah ini:

Tabel 3. Hasil Uji Normalitas

\begin{tabular}{cccc}
\hline \multirow{2}{*}{ Data } & \multicolumn{2}{c}{ Asym Sig $>\boldsymbol{0 , 0 5}$} & \multirow{2}{*}{ Keterangan } \\
\cline { 2 - 3 } & Asym Sig. & $\boldsymbol{\alpha}$ & \\
\hline Pretest & 0,282 & 0,05 & Normal \\
Posttest & 0,134 & & Normal \\
\hline
\end{tabular}

Pengujian normalitas suatu data dapat dilihat dari besarnya taraf signifikan, yaitu sebesar a = 0,05 dibandingkan dengan nilai Asymp. Sig. (2tailed), dengan kaidah keputusan apabila nilai Asymp. Sig. (2-tailed) >0,05 maka data tersebut berdistribusi normal.

Uji homogenitas dimaksudkan untuk memperlihatkan bahwa dua atau lebih kelompok data sampel berasal dari populasi yang memiliki varians yang sama. Seperti yang telah dijelaskan di atas, bahwa sebelum melakukan uji hipotesis, maka salah satu persyaratannya adalah uji homogenitas data yang akan diuji. Hasil uji homogenitas data tampak pada tabel 4 di bawah ini:

Tabel 4. Hasil Uji Homogenitas

\begin{tabular}{cccc}
\hline \multirow{2}{*}{ Data } & \multicolumn{2}{c}{ Sig $>\mathbf{0 , 0 5}$} & \multirow{2}{*}{ Keterangan } \\
\cline { 2 - 3 } & Sig. & $\boldsymbol{\alpha}$ & \\
\hline $\begin{array}{c}\text { Data Awal } \\
\text { Data Akhir }\end{array}$ & 0,094 & 0,05 & Homogen \\
\hline
\end{tabular}


Homogenita suatu data dapat diketahui dengan cara membandingkan taraf signifikasi a = 0,05 dengan nilai signifikansi pada uji statistik, dengan kaidah keputusan apabila nilai signifikansi $>0,05$ maka varians setiap sampel sama (homogen).

Setelah dilakukan uji normalitas dan uji homogenitas data dan diketahui hasil dari pengujian-pengujian tersebut berdistribusi normal dan homogen, maka data penelitian tersebut layak dipakai untuk melakukan analisis uji parametik. Tabel 5 menunjukkan hasil uji paired sample t-test. Dari hasil uji statistik tersebit diketahui bahwa nilai Sig. $=0,000<0,05$, artinya ada perbedaan kempuan dribbling peserta didik sebelum dan sesudah pemberian perlakuan, yaitu pembelajaran dengan pendekatan permainan.

Tabel 5. Uji Hipotesis

\begin{tabular}{cccccccc}
\hline Set & Mean & SD & $\boldsymbol{t}_{\text {hitung }}$ & $\boldsymbol{\alpha}$ & $\boldsymbol{t}_{\text {tabel }}$ & Sig. & $\begin{array}{c}\text { Keteranga } \\
\boldsymbol{n}\end{array}$ \\
\hline Pretest & 14,94 & 4,007 & 3,312 & 0,05 & 1,75 & 0,000 & Signifikan \\
\hline Posttest & 16,17 & 4,065 & 3,312 &
\end{tabular}

\section{PEMBAHASAN}

Hasil penelitian ini merupakan petunjuk bahwa pendekatan permainan ternyata mempengaruhi hasil belajar dribbling sepak bola pada kelas XI SMA Negeri 10 Palembang. Pendekatan permainan sesuai dengan karakter peserta didik SMA Negeri 10 Palembang yang senang dengan pola pembelajaran menggunakan basis-basis permainan. Permainan adalah kegiatan yang menyenangkan, kegiatan ini sebagai bentuk alat bantu proses pembelajaran yang efektif, hal ini sesuai dengan pendapat (Amirzan, 2021) menyatakan bahwa permainan merupakan alat yang dapat digunakan untuk membantu proses pembelajaran pendidikan jasmani dan menunjang tercapainya tujuan belajar.

Kemempuan menggiring dalam sepak bola sangat penting untuk dikuasai oleh peserta didik untuk dapat mengembangkan teknik dasar lainnya dalam permaiann sepak bola (Rahmatullah, 2021). Hal ini juga didukung oleh penelitian sebelumnya yang menyatakan bahwa keterampialn menggiring dalam sepak bola merupakan salah satu penentu dalam 
keberhasilan peserta didik untuk dapat menguasai teknik dasar sepak bola secara keseluruhan (Erfayliana \& Wati, 2020). Peningkatan keterampilan dasar menggiring dalam sepak bola juga banyak telah diteliti oleh guru dan akademisi (Aprianova \& Hariadi, 2016; Sari et al., 2021; Wijaya et al., 2021), dan metode dalam memberikan materi menggiring dalam permaian sepak bola harus menyesuaikan dengan karakteristik peserta didik (Affandy, 2017). Penelitian ini masih merupakan penelitian semu, sehingga masih perlu penelitian lanjutan untuk dapat benar-benar membuktikan bahwa metode permainan dapat diterapkan dalam pembelajaran pendidikan jasmani untuk materi sepak bola, terutama pada jenjang pendidikan dasar dan menengah.

\section{KESIMPULAN}

Berdasarkan hasil penelitian yang telah didapatkan, maka kesimpulan dari penelitian ini adalah pembelajaran dengan pendekatan bermain dapat meningkatkan hasil belajar dribbling peserta didik pada satuan pendidikan Sekolah Menengah Atas (SMA). Penelitian ini juga memperkaya metode pembelajaran yang dapat diterapkan oleh guru pendidikan jasmani untuk materi sepak bola.

\section{KONTRIBUSI PENULIS}

Author 1: Writing; Review \& Editing. Author 2: Methodology; Validating. Author 3: Original Draft.

\section{DAFTAR PUSTAKA}

Abdullah, R. (2012). Pembelajaran Berbasis Pemanfaatan Sumber Belajar. Jurnal Ilmiah Didaktika, 12(2), 216-231. https://doi.org/10.22373/jid.v12i2.449

Affandy, S. (2017). Penerapan Model Pembelajaran Kooperatif Tipe Jigsaw Terhadap Hasil Belajar Teknik Dasar Dribbling Dan Passing Sepakbola (Studi pada Peserta Didik Kelas VII SMP Negeri 2 Sooko Mojokerto). Jurnal Pendidikan Olahraga Dan Kesehatan, 5(3), 496-500. http:/ / ejournal.unesa.ac.id/index.php/jurnal-pendidikanjasmani/issue/archive

Amirzan, S. (2021). Pengaruh pendekatan bermain terhadap kesegaran jasmani siswa SMA Negeri 1 Sigli. Education Enthusiast: Jurnal Pendidikan Dan Keguruan, 1(1), 34-46. 
http://journal.unigha.ac.id/index.php/EE/article/view/272

Aprianova, F., \& Hariadi, I. (2016). Metode Drill Untuk Meningkatkan Teknik Dasar Menggiring Bola (Dribbling) Dalam Permainan Sepakbola Pada Siswa Sekolah Sepakbola Putra Zodiac Kabupaten Bojonegoro Usia 1315 Tahun. Jurnal Kepelatihan Olahraga, 1(1), 63-74. http://journal.um.ac.id/index.php/jko/article/view/7709

Bailey, R. (2018). Sport, physical education and educational worth. Educational Review, 7O(1), 51-66. https://doi.org/10.1080/00131911.2018.1403208

Erfayliana, Y., \& Wati, O. K. (2020). Tingkat Keterampilan Dasar Bermain Sepakbola Peserta Didik Kelas Atas Sekolah Dasar. TERAMPIL: Jurnal Pendidikan Dan Pembelajaran Dasar, 7(2), 159-166. https://doi.org/10.24042/TERAMPIL.V7I2.8119

Irawan, A. Y., \& Hariadi, I. (2019). Hubungan antara Kecepatan dan Kelincahan dengan Keterampilan Menggiring Bola. Sport Science and Health, 1(3), 222-226. http://journal2.um.ac.id/index.php/jfik/article/view/11359

Lacy, A. C., \& Williams, S. M. (2018). Measurement and Evaluation in Physical Education and Exercise Science. In Measurement and Evaluation in Physical Education and Exercise Science (6th ed.). Pearson Benjamin. https://doi.org/10.4324/9781315312736

Martin, M., \& Morris, M. (2013). Sport education and multiple intelligences: A path to student success. Strategies, 26(4), 31-34. https://doi.org/10.1080/08924562.2013.799931

Rahmatullah, M. I. (2021). Analisis kelincahan, kecepatan, dan koordinasi mata-kaki dengan kemampuan dribbling tim sepak bola uss (uir soccer school). Journal of Sport Education (JOPE), 3(2), 137. https://doi.org/10.31258/jope.3.2.137-145

Rusman. (2013). Model Pembelajaran Mengembangkan Profesionalisme Guru, Model Pembelajaran Mengembangkan Profesionalisme Guru (2nd ed.). Rajagrafindo Persada. http://www.rajagrafindo.co.id/produk/modelmodel-pembelajaran/

Saputra, M. R. E., \& Yunus, M. (2019). Pengembangan Variasi Model Latihan Dribbling Sepakbola untuk Atlet Usia 13-15 Tahun | Saputra | Indonesia Performance Journal. Indonesia Performance Journal, 3(1), 815. http://journal2.um.ac.id/index.php/jko/article/view/10079

Saputra, R., \& Maidarman. (2019). Studi Keterampilan Teknik Dasar Sepakbola. Jurnal Patriot, 1(1), 14-20. https://doi.org/10.24036/PATRIOT.V1I1.43

Sari, D., Supriyadi, M., Syafutra, W., \& Okilanda, A. (2021). Modifikasi Latihan Permainan Sepak Bola untuk Meningkatkan Keterampilan Menggiring Bola Pada Peserta SSB Silampari Tugumulyo. Jurnal Patriot, 3(2), 192-202. https://doi.org/ 10.24036/PATRIOT.V3I2.790 
Sudjana. (2011). Metode Statistika. Tarsito.

Susanto, A. (2016). Teori Belajar dan Pembelajaran di Sekolah Dasar (Cetakan ke-4). In Jakarta: Prenadamedia Group (Vol. 2). Prenadamedia Group.

Wijaya, B. R., Usra, M., Flora, R., Iyakrus, \& Bayu, W. I. (2021). Efektivitas Model Latihan Kombinasi untuk Meningkatkan Keterampilan Menggiring dan Mengumpan dalam Permainan Sepak Bola. Journal of Sport Coaching and Physical Education, 6(2), 69-76. https://doi.org/ 10.15294/JSCPE.V6I2.48062 